\title{
ÇEŞITTLİ MADEN SULARINDA ANYON VE KATYON MİKTARLARININ BELİRLENMESİ
}

\author{
Yağmur Oruç ${ }^{1, *}$, Belgin İzgi $^{2}$ \\ ${ }^{1}$ Uludağ İçecek Türk A.Ş., Ar\&Ge Merkezi, Yeniceköy mah, İnegöl, Bursa, Türkiye \\ ${ }^{2}$ Bursa Uludağ Üniversitesi, Fen-Edebiyat Fakültesi, Kimya Bölümü, Nilüfer, Bursa, Türkiye
}

Geliş / Received: 29.05.2019; Kabul / Accepted: 08.11.2019; Online bask1 / Published online: 24.02.2020

Oruç, Y., İzgi, B. (2019). Çeşitli maden sularında anyon ve katyon miktarlarının belirlenmesi. GIDA (2020) 45(2) 242-252 doi: 10.15237/gida.GD19092.

Oruc, Y., İggi, B. (2019). Determination of anion and cation amounts in various mineral waters. GIDA (2010) 45(2) 242-252 doi: 10.15237/gida.GD19092.

\section{ÖZ}

Maden suyu insan sağllğı açısından yararlı mineralleri yüksek oranda bünyesinde bulunduran doğal bir gida ürünüdür. Bu mineraller insan vücudunda sentezlenemez ve dışarıdan alınmalıdır. Çalışmanın amacı, maden sularının mevcut mineral içeriği üzerine katkı maddelerinden gelebilecek olumlu/olumsuz etkilerinin olup olmadığı yanı sıra bu sınıftaki içeceklerin gerçekten zengin mineralli su ile hazırlanıp/hazırlanmadığının belirlenmesidir. Çalışma kapsamında; ticari olarak piyasada bulunan 4 farklı kategoride; sade, aroma, meyve konsantresi ve vitamin katkılı maden suyu çeşitlerinde iletkenlik detektörlü iyon kromatograsi (IC-CD) kullanilarak, anyon $\left(\mathrm{Cl}, \mathrm{F}-, \mathrm{NO}_{2}^{-}, \mathrm{NO}_{3}^{-}, \mathrm{PO}_{4}^{3-}, \mathrm{SO}_{4}^{2-}\right)$ ve katyon $\left(\mathrm{Na}^{+}, \mathrm{NH}_{4}^{+}, \mathrm{K}^{+}, \mathrm{Mg}^{2+}, \mathrm{Ca}^{2+}\right)$ içerikleri kıyaslanmıştır. $\mathrm{SO}_{4}$ için; katkısız maden suyunda, aroma, vitamin ve meyve katkılı maden suyunda konsantrasyonları sirası ile $24.55 \mathrm{mg} / \mathrm{L}, 21.52 \mathrm{mg} / \mathrm{L}, 21.20 \mathrm{mg} / \mathrm{L}$ ve $55.08 \mathrm{mg} / \mathrm{L}$ olarak tespit edildi. K için ise; katkısız maden suyunda, aroma, vitamin ve meyve katkılı maden suyunda konsantrasyonları sırası ile $27.97 \mathrm{mg} / \mathrm{L}, 22.51 \mathrm{mg} / \mathrm{L}, 26.10 \mathrm{mg} / \mathrm{L}$ ve $185.60 \mathrm{mg} / \mathrm{L}$ olarak tespit edildi.

Anahtar Kelimeler: Anyon, doğal maden suyu (maden mineralli sular), iyon kromatografisi, Katyon

\section{DETERMINATION OF ANION AND CATION AMOUNTS IN VARIOUS MINERAL WATERS}

\begin{abstract}
Spring mineral water contains minerals in itself that is beneficial for human health. These minerals are not synthesized in the human body, and they should be taken from outside. The aim of the study is to determine whether the mineral waters have positive/negative effects on the mineral content of the additives and the determination of using / disuse mineral water when preparing products. In this study, four different categories were compared in the local market: standard mineral water, flavored mineral water, fruity mineral water, and mineral water with vitamin. Anion $\left(\mathrm{Cl}^{-}, \mathrm{F}-\mathrm{NO}_{2}^{-}, \mathrm{NO}_{3}^{-}, \mathrm{PO}_{4}{ }^{3-}\right.$ , $\left.\mathrm{SO}_{4}{ }^{2-}\right)$ and cation $\left(\mathrm{Na}^{+}, \mathrm{NH}_{4}{ }^{+}, \mathrm{K}^{+}, \mathrm{Mg}^{2+}, \mathrm{Ca}^{2+}\right)$ compounds were determined by ion chromatography with conductivity detector (IC-CD). Result of SO $24.55 \mathrm{mgL}^{-1}, 21.52 \mathrm{mg} \mathrm{L}^{-1}, 21.20 \mathrm{mg} \mathrm{L}^{-1}$, and 55.08 $\mathrm{mg} \mathrm{L}^{-1}$ for standard, flavored, fruity mineral water, and mineral water with vitamin.
\end{abstract}

Keywords Anion, cation, ion chromatography, natural mineral water

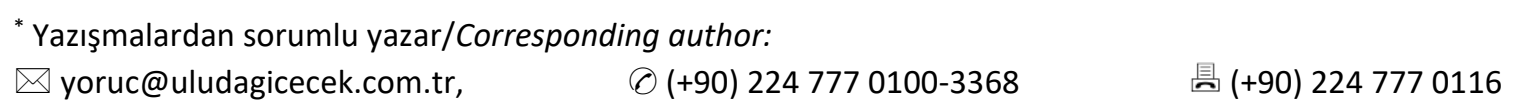

Yağmur Oruç; ORCID no: 0000-0001-9043-4264

Belgin İzgi; ORCID no: 0000-0002-1074-3612 


\section{GİRİ̧̧}

Mineralli su; çözünmüş mineral tuzları, elementler ve gaz içermektedir. Genel olarak, jeolojik ve fiziksel olarak koruma altında tutulan yeraltı sularından kuyu açlarak veya kaynaktan doldurularak elde edilmektedir (T.C. Sağllk Bakanllğ1 Doğal Mineralli Sular Rehber Kitab1, 2008). Kar ve yağmur gibi yüzey suları çeşitli yollar ile zamanla yer altına sizmaktadirlar. 10-100 yil arası depolanan bu sular bulundukları ortamdaki kayaçların özelliklerine göre çeşitli mineralleri bünyesine alırlar. Bünyelerine aldıkları mineraller $1000 \mathrm{mg} / L$ 'ye ulaştığında sular geleneksel adı olan maden suyu özelliği kazanmış olur (Gezer, 2016; Gültekin ve Dilek,2005). Maden suyu içerisinde bulundurduğu zengin mineraller sebebi ile içme sularına oranla sertliği daha yüksek olduğu için halk arasinda 'acı su' diye de tabir edilir (Kopar, 2002). Bu özelliğinin yanında gida endüstrisi alanında maden suyunun içimini kolaylaştırmak ve mikrobiyolojik oluşumlanı engellemek açısından karbondioksit ilavesi yapılmaktadır.

01.12.2004 tarihli ve 25657 sayll resmi gazetede yayınlanan, Doğal mineralli sular hakkındaki yönetmelikte; mineralli suların tanımı; 'Yerkabuğunun çessitli derinliklerinde uygun jeolojik sartlarda doğal olarak oluşan, bir veya daha fazla kaynaktan yeryürüne kendilig̈inden çıkan veya teknik usullerle çıkartılan, mineral içeriği, kalint elementleri ve diğer bilessenleri ile tammlanan, ber türlü kirlenme riskine karşı korunmus, mikrobiyolojik yönden uygun yönetmelikte belirtilen kimyasal parametrelere uygun su' olarak tanımlanmaktadır (Anonymous, 2013).

Bu bilgilerin yanında doğal mineralli sularla ilgili olarak aynı yönetmelikte, Madde 25 içinde yer verilen ve "Piyasada veya tanitımlarda doğal mineralli suyun ibtiva ettiği maddelerin veya doğal mineralli suyun önemli bir niteliğinin vurgulanması açısından aşağgda belirtilen bususlara uyulur" ifadesine göre de doğal mineralli suların farklı şekillerde sinıflandırılması da yapılmaktadır. Aşağıda kısaca bu sinıflandırılma özetlenmiştir.

Katı tortu olarak hesaplanan mineral miktarına göre;

$1500 \mathrm{mg} / \mathrm{L}$ 'nin üzerinde ise "zengin mineralli" $500 \mathrm{mg}$ /L'nin üzerinde ise "düşük mineralli”,
$50 \mathrm{mg} / \mathrm{L}$ 'nin altında ise "çok düşük mineralli" adinı alır.

Ayrıca isimlendirme için bileşen içeriğine göre de aşağıdaki şekilde;

bikarbonat değeri $600 \mathrm{mg} / \mathrm{L}$ 'nin üzerinde ise "Bikarbonatli",

sülfat değeri $200 \mathrm{mg} / \mathrm{L}$ 'nin üzerinde ise "Sülfatlı", klorür değeri 200 mg/L'nin Klorürlü,

kalsiyum değeri $150 \mathrm{mg} / \mathrm{L}$ 'nin üzerinde ise "Kalsiyumlu",

magnezyum değeri $50 \mathrm{mg} / \mathrm{L}$ 'nin üzerinde ise "Magnezyumlu",

çift değerli Demir değeri 1mg/L'nin üzerinde ise "Demirli",

florür değeri $1 \mathrm{mg} /$ L'nin üzerinde ise "Florürlü", sodyum değeri $200 \mathrm{mg} / \mathrm{L}$ 'nin "Sodyumlu",

ibarelerini alır. (Anonymous, 2013)

Sıcak ve soğuk mineralli su kaynakları açısından Türkiye, dünyada ilk 7 ülke arasinda yer almaktadır. Bunun en önemli sebebi, coğrafi konumunda volkanik ve tektonik arazilerin oldukça fazla olmasıdır. Ülkemizde toplam 1300 adet farklı debilerde mineralli su kaynağ1 bulunmaktadır. Bu kaynaklara kaplıca, 1lıca gibi termal su kaynakları da dâhildir (Toroğlu ve Ceylan, 2013; Korkmaz, Karataş; 2011).

Vücudun dengeli bir şeklide büyüyüp gelişmesi için makro minerallere ve eser elementlere ihtiyacı vardır. $\mathrm{Bu}$ mineraller de maden suyu içerisinde bolca bulunmaktadır. Vücudun günlük gereksinimi 250 mg'ın üzerinde olan minerallere makro mineraller, günlük gereksinimi 20 mg'in altında olan minerallere ise eser element denir. Makro minerallere sodyum, potasyum, kalsiyum gibi mineraller örnek verilirken, eser elementlere ise demir, çinko, selenyum örnek verilebilir.

Minerallerin yetersiz alınımı ya da hiç alınmaması insan sağlığında olumsuz etkilere sebep olabilir. $\mathrm{Bu}$ olumsuz etkilere, öğrenme yeteneğinde azalma, zihinsel problemler, enfeksiyon riskinde artış, düşük çalışma kapasitesi, görme bozukluğu ve prematüre ölümler örnek verilebilir. Bu tür rahatsızlıklar büyüme, gelişme ve yaşam kalitesi açısından yarattı̆̆ı olumsuz etkiler sebebi ile ulusların, sosyal ve ekonomik potansiyelinde 
önemli kayılar yaratmaktadır (Mete ve Altuner, 2017; Samur, 2008). Magnezyum alınımı kroner arter hastallklara, havaleye ve insülin direncine karş1 koruyucu bir etkiye sahiptir. Yaklaşık 350 enzimde kofaktör olarak, protein ve nükleik asitlerin sentezinde görev alır. Ayrıca ATP sentezine yardımcı olarak enerji üretimini sağlar. Çinko, selenyum, magnezyum ise metabolik yollarda kataliz olarak görev alarak hormonal fonksiyonlarda etkin rol oynar. Sodyum, klor, potasyum gibi iyonlar ise vücuttaki su-elektrolit dengesini sağlar. Yine Kalsiyum, fosfor, magnezyum, flor gibi mineraller kemik ve zar yapilarında bulunur. Ayrica vücuda alınan kalsiyumun menopoz sonrasi osteoporoz göstergelerinde azaltıcı etkiye sahip olduğu ve kardiyovasküler hastalı potansiyelini azaltmaya yardımcı olduğu yapılan çalışmalar ile kanıtlanmıştır (Gatarska vd., 2016; Balcığlu, 2013; Manaver vd., 2017; Danone Nutritopics Magazine, 2007). Futbolcular ile yapilan bir çalışmada ise, maden suyunun vücuttaki elektrolit dengesini iyi düzenlediği ortaya çıkmıştır (Kara vd., 2012).

Ülkemizde bu kadar fazla mineralli su kaynağ1 bulunmasina ve maden suyunun içerisinde bulunan zengin mineral düzeyinin sağlığa olumlu etkisine rağmen, maden suyu tüketimi oldukça azdır. Ülkemizde kişi başına düşen maden suyu tüketim değeri 2002'de 2.5 L iken 2010 yllında 6.5 L'ye ulaşmıstır. Ancak Avrupa'daki tüketimin y1llık 120 L olduğu düşünülürse ülkemizdeki tüketim miktarı Avrupa ülkelerine göre oldukça azdır (Kızıloğlu,2013; TURKSTAT, 2011; FAO, 2011). Günümüzde üreten ve geliştiren toplumlarda sanayinin payı oldukça büyüktür. Ülkemizde sanayide gıda endüstrisi, önemli bir yerdedir. Gida endüstrisinde inovasyon yapilırken toplum sağlığı doğrudan düşünülmek zorundadır. Mineralli maden sularının tüketiminin arttırılması adına yapilan en önemli inovasyonlardan biri, aromalı ve meyveli maden sularının piyasaya sürülmesidir. Maden suyuna getirilen bu iki yeni çeşit ile maden suyu tüketiminin arttırılmasina katk1 sağlanmıştır. Bu tür ürünler, toplumun her yaştan ve cinsiyetten kesimine yönelik olması ve özellikle aromalı maden sularının diğer içeceklere göre pazar fiyatının düşük olması gibi etmenlerden dolayı çok fazla ilgi görmesine neden olmuştur.

Maden sularının gerçekte bulundurması gereken mineral miktarının tespit edilmesinde çeşitli yöntemler kullanılmaktadır. Bu yöntemler başlıca spektrofotometrik, kromatografik ve titrimetrik yöntemlerdir. Titrimetrik yöntemde, çeşitli dönüm noktalarına göre (renk değiştirme, çökelti oluşturma gibi) analiz yapilırken, spektrofotometrik ve kromatografik yöntemlerde ise ileri teknikteki cihazlar ile kalitatif ve kantitatif ölçümler yapılabilmektedir. Maden sularının analizlerinde spektrofotometrik olarak en çok indüktif eşleşmiş plazma- optik emisyon spektrometresi (ICP-OES), indüktif eşleşmiş plazma-kütle spektrometresi (ICP-MS), alevli atomik absorpsiyon spektrometresi (Alevli-AAS), elektro termal atomik absorpsiyon spektrometresi (ET-AAS) gibi yöntemler kullanılırken, kromatografik olarak İyon Değişim Kromatografisi yöntemi (IC) sılikla kullanılmaktadır.

IC'nin çalışma prensibine kısaca bakıldığında, iyon değiştirici kolonda ayrımı sağlanan anyonlar ya da katyonlar suppressor adı verilen baskilama aracina gönderilirler. Burada hareketli fazdan gelen iyonlar baskılanırken, analitlerin iletkenliği arttırllır. İletkenliği arttırılmış analitlerin çeşitli dedektörler sayesinde analizi yapılır. Dedektöre ulaşan derişimi bilinen standart içerisindeki analit miktarının alanına ya da yüksekliğine göre çizilen kalibrasyon eğrisi yardımı ile, bilinmeyen örnekteki analit miktarının dedektörde verdiği alanı ya da yüksekliği kullanılarak derişimi tespit edilir (Cataldi, vd. 2002; Ramzan vd. 2012).

Bu çalışmada Türkiye piyasasında bulunan zengin mineralli içeceklerde anyon katyon analizleri yapılmıştır. Sade, aroma katkılı, meyve (konsantre) katk1lı ve vitamin katk1lı olmak üzere 4 farklı kategoride yer alan maden sularının, birbirleriyle ve kendi içlerinde kıyaslaması yapılmıştır. Örnekler ultra saf su ile seyreltilerek analize hazır hale getirilmiş. Tüm analizler IC-CD ile gerçekleştirilmiştir. 


\section{MATERYAL VE YÖNTEM}

\section{Materyal}

Deneysel çalışmada kullanılan tüm kimyasallar kromatografik saflıktadır. Hareketli faz olarak oksalik asit, sodyum karbonat ve sodyum bikarbonat kullanılmıştır (Merk, Darmstadt, Germany). Standartlar tekli halde alınmış olup, analiz sırasında standart karışımı haline getirilmiştir. Kullanılan standartlar; klorür, florür, nitrit, nitrat, fosfat, sülfat, sodyum, amonyum, potasyum, kalsiyum, magnezyumdur (AccuStandard, New haven, ABD). Ultra saf su Millipore Direct-Q UV deiyonizasyon su sistemi kullanılarak hazırlanmıştır (Burlington, ABD).

\section{Standart Hazırlama}

Anyon standart çözeltileri $\left(\mathrm{Cl}^{-}, \mathrm{F}^{-}, \mathrm{NO}_{2}^{-}, \mathrm{NO}_{3}^{-}\right.$, $\mathrm{PO}_{4}{ }^{3-}, \mathrm{SO}_{4}{ }^{2-}$ ), ultra saf su ile 3 noktalı olacak şekilde uygun derişimlere seyreltilerek hazırlanmıştır. Katyon standart çözeltileri $\left(\mathrm{Na}^{+}\right.$,
$\left.\mathrm{NH}_{4}^{+}, \mathrm{K}^{+}, \mathrm{Mg}^{2+}, \mathrm{Ca}^{2+}\right)$, de aynı uygulama ile hazırlanmıştır.

\section{Örnek Hazırlama}

Bu çalışmada, toplamda 17 çeşit mineralli su ile hazırlanmış içeceğin analizi gerçekleştirilmiştir. Standart maden suyu sınıfinda 2 çeşit farklı $\mathrm{CO}_{2}$ oranına sahip numuneler kullanılmıştır. Aromalı maden suları sınıfında elma, limon, şeftali, çilek, karpuz \& çilek olmak üzere 5 çeşit farklı aromaya sahip numune kullanılmıştır. Meyve katkılı maden sularında narlı, mandalinalı, kavunlu, yeşil limonlu, çarkıfelek meyveli, armutlu ve karışık orman meyveli olmak üzere 7 farklı çeşit numune kullanılmıștır. Vitamin katkı1ı tüm maden sularında vitamin $\mathrm{B} 3, \mathrm{~B} 5, \mathrm{~B} 6, \mathrm{~B} 9$ ve $\mathrm{B} 12$ ve $\mathrm{C}$ vitamini katkilı ancak limon, portakal ve kivi olmak üzere farklı aroma tipinde 3 numune tercih edilmiştir. Örnek hazırlama basamağı Şekil 1'de özetlenmiştir.

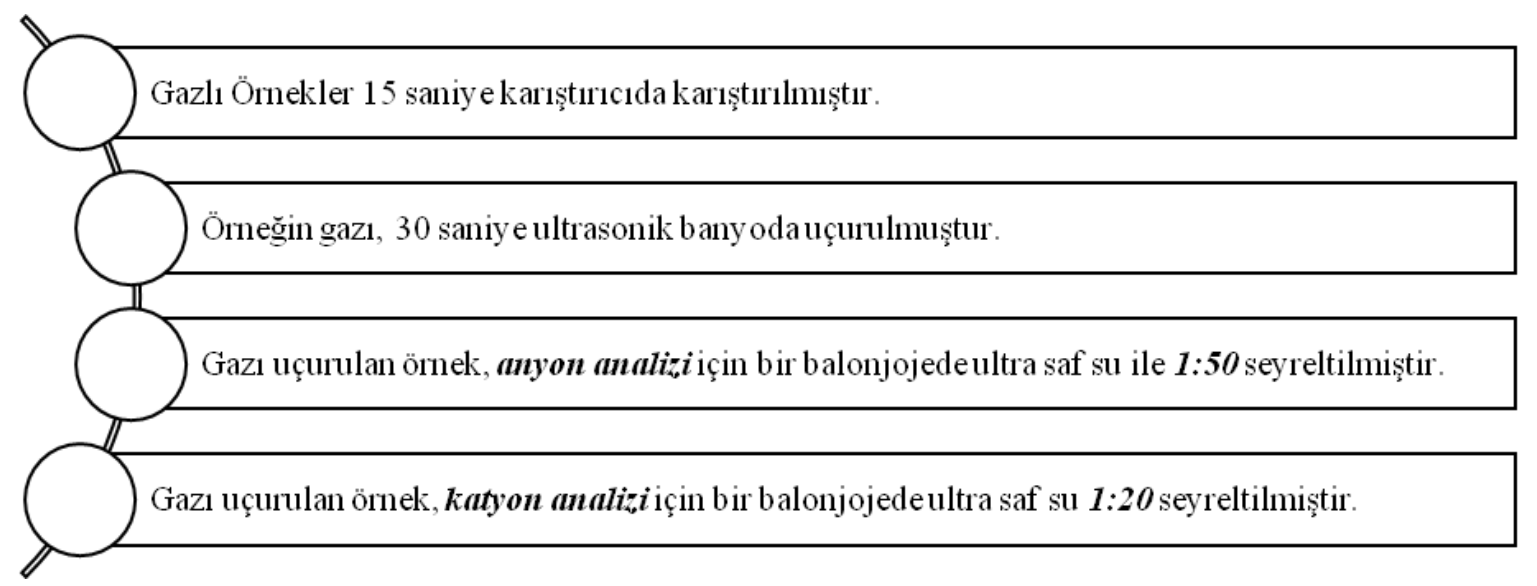

Şekil 1 Örnek hazırlama basamağ1

Fig 1 Step of sample preparation

Örnekler 3 tekrarlı olacak şekilde hazırlanarak analiz edilmiştir. Analiz sonuçlarında numune isimleri firmaların gizliliğinin korunması için kodlama yapılarak verilmiştir.

\section{Cihaz şartları}

Analizler IC-CD ile gerçekleştirilmiştir (CBM$20 \mathrm{~A}$ Veri modülü, 2 adet LC-20AD sp pompa ünitesi, CTO-20AC sp kolon firını, CDD-10A sp iletkenlik detektörü). Katyon ayrımında Shimpack IC-C4 kuaterner amonyum gruplu katyon değiştirici kolon $(150 \times 4.6 \mathrm{~mm})$ ve Shim-pack IC
GC4 katyon değiştirici kolon için koruyucu kolon kullanılmıştır. Anyon analizinde ise Shim-pack IC-SA2 karboksil gruplu anyon değiştirici kolon $(150 \times 4.0 \mathrm{~mm})$ ve Shim-pack IC-SA2(G) anyon değiştirici kolon için koruyucu kolon kullanılmıştır. Yine anyon analizi için Shimadzu $\mathrm{P} / \mathrm{N}$ 228-40612-91 anyon suppressorü ve kartuşu kullanılmışır (Shimadzu, Kyto, Japonya).

Anyon analizi olarak, EPA 300.0 metodu üzerinde bazı değişiklikler yapılarak oluşturulan in-house bir metot kullanılmıştır. Analizler, suppressor 
sistemi açık olarak yapılmıştır. Mobil faz olarak, $1.8 \mathrm{mM}$ Sodyum karbonat $\left(\mathrm{Na}_{2} \mathrm{CO}_{3}\right), 1.7 \mathrm{mM}$ Sodyum bikarbonat $\left(\mathrm{NaHCO}_{3}\right)$ olacak şekilde ultra saf su ile hazırlanarak kullanılmıştır. Kolon olarak kuaterner amonyum grubu bağlı kolon ve buna uygun ayırıcı kolon kullanılmıştır. Mobil faz Șekil-2

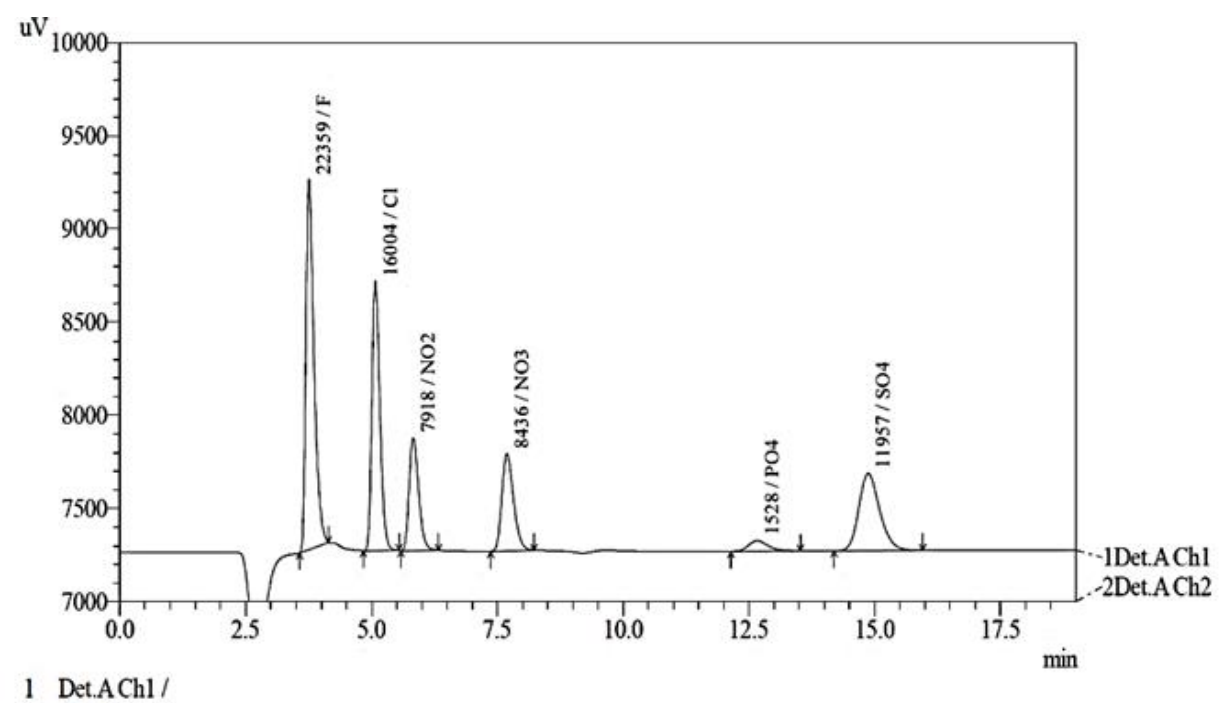

Şekil 2 Anyon için standartların kromatogramı

Fig 2 Chromatogram of anion standards

Katyon analizi olarak, ASTM D6919-03 metodu üzerinde bazı değişiklikler yapılarak oluşturulan in-house bir metot kullanılmıştır. Analizler, suppressor sistemi kapalı olarak yapılmıştır. Mobil faz için $2.5 \mathrm{mM}$ oksalik asit $\left(\mathrm{C}_{2} \mathrm{H}_{2} \mathrm{O}_{4}\right)$ ultra saf su ile hazırlanmıştır. Kolon olarak karboksil grubu bağlı kolon ve buna uygun koruyucu kolon izobarik akışta, akış hızı $1 \mathrm{~mL} / \mathrm{dk}$ olacak şekilde ayarlanmıştır. Kolon sıcaklığı $30^{\circ} \mathrm{C}$, enjeksiyon hacmi $20 \mu \mathrm{L}$, analiz süresi 19 dakikadır. (Michalski, 2006; EPA, 1993) Anyon analizi için laboratuvarda uygulanan standartlarin kromatogramı Şekil 2'deki gibidir.

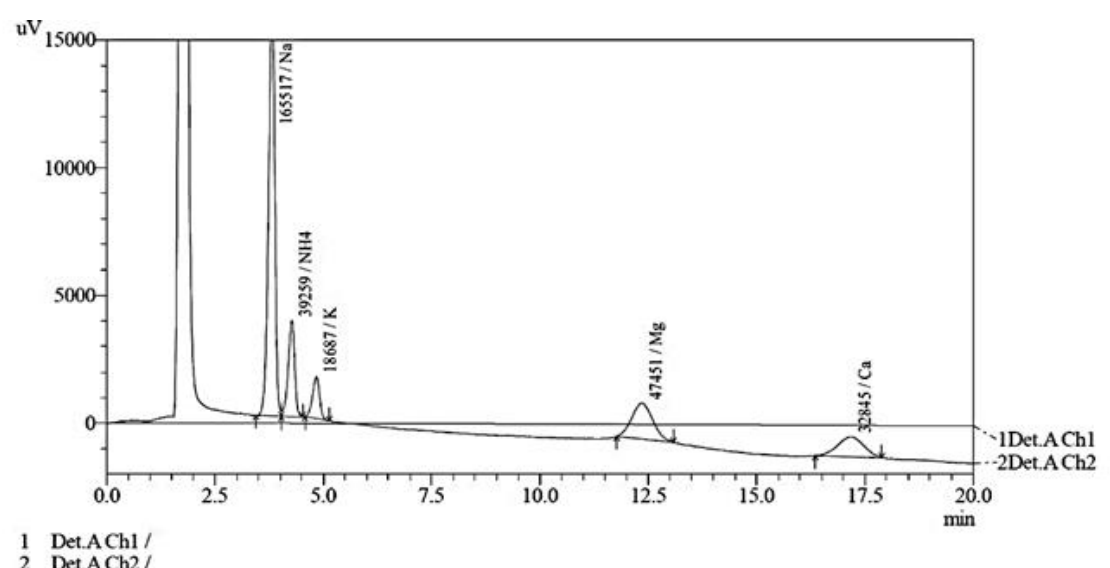

Şekil 3 Katyon için standartların kromatogramı

Fig 3 Chromatogram of cation standards 


\section{SONUÇ VE TARTIŞMA}

Anyon analizi için lineer çalışma aralığı, regresyon katsayısı ve geri kazanım çalışması sonucu Çizelge 1'deki gibidir.

Çizelge 1. Anyon analizi için Lineer aralık, regresyon katsayı, eklenen miktar, elde edilen miktar ve yüzde geri kazanım değerleri/

Table 1 Linear range, correlation coefficiencies, Recovery (\%) of anions.

\begin{tabular}{|lccccc|}
\hline Anyonlar & $\begin{array}{c}\text { Lineer Aralik } \\
(\mathrm{mg} / \mathrm{L})\end{array}$ & $\begin{array}{c}\text { Regresyon } \\
\text { Katsayıs }\end{array}$ & $\begin{array}{c}\text { Eklenen Miktar } \\
(\mathrm{mg} / \mathrm{L})\end{array}$ & $\begin{array}{c}\text { Elde Edilen } \\
\text { Miktar }\end{array}$ & $\begin{array}{c}\text { \%Geri } \\
\text { Kazanım }\end{array}$ \\
\hline \hline $\mathrm{F}^{-}$ & $0.25-0.5-1$ & 0.9996 & 1.00 & 1.03 & 103 \\
$\mathrm{Ct}$ & $0.25-0.5-1$ & 0.9996 & 1.00 & 1.09 & 109 \\
$\mathrm{NO}^{-}$ & $0.25-0.5-1$ & 0.9987 & 1.00 & 0.98 & 98 \\
$\mathrm{NO}_{3}^{-}$ & $0.25-0.5-1$ & 0.9978 & 1.00 & 1.01 & 101 \\
$\mathrm{PO}_{4}^{-}$ & $0.25-0.5-1$ & 0.9999 & 1.00 & 0.96 & 96 \\
$\mathrm{SO}_{4}{ }^{-2}$ & $0.25-0.5-1$ & 0.9966 & 1.00 & 1.01 & 101 \\
\hline
\end{tabular}

Anyon analizi için kalibrasyon eğrisi için lineer çalışma aralığı, regresyon katsayısı ve geri kazanım çalısması sonucu Çizelge 2'deki gibidir.

Çizelge 2. Katyon analizi içim Lineer aralık, regresyon katsayı, eklenen miktar, elde edilen miktar ve yüzde geri kazanım değerleri

Table 2 Linear range, correlation coefficiencies, Recovery (\%) of cations

\begin{tabular}{|lccccc|}
\hline Katyonlar & $\begin{array}{c}\text { Lineer Aralik } \\
(\mathrm{mg} / \mathrm{L})\end{array}$ & $\begin{array}{c}\text { Regresyon } \\
\text { Katsayls1 }\end{array}$ & $\begin{array}{c}\text { Eklenen Miktar } \\
(\mathrm{mg} / \mathrm{L})\end{array}$ & $\begin{array}{c}\text { Elde Edilen } \\
\text { Miktar }\end{array}$ & $\begin{array}{c}\text { \%Geri } \\
\text { Kazanim }\end{array}$ \\
\hline \hline $\mathrm{Na}^{+}$ & $1.25-2.5-5$ & 0.9980 & 5.00 & 4.68 & 94 \\
$\mathrm{NH}_{4}{ }^{+}$ & $0.25-0.5-1$ & 0.9975 & 1.00 & 1.04 & 104 \\
$\mathrm{~K}^{+}$ & $0.25-0.5-1$ & 0.9974 & 1.00 & 1.00 & 100 \\
$\mathrm{Mg}^{2+}$ & $0.25-0.5-1$ & 0.9996 & 1.00 & 0.99 & 99 \\
$\mathrm{Ca}^{2+}$ & $0.25-0.5-1$ & 0.9999 & 1.00 & 1.05 & 105 \\
\hline
\end{tabular}

Her iki grup için regresyon değerleri 0.99 ve üzerinde saptanmıştır. Yüzde geri kazanım çalışması için sodyum (sodyum için $5 \mathrm{mg} / \mathrm{L}$ ) hariç tüm analizler $1 \mathrm{mg} / \mathrm{L}$ olacak şekilde maden suyu matriksine ilave (spike) edilerek yapılmıştır. Çalışma sonunda yüzde geri kazanımların \%93108 arasında olduğu görülmüştür. Standart maden suyu çeşitleri için analiz sonuçları Çizelge 3’teki gibidir.

Üretim tarihleri farklı iki katkısız maden sularının analiz sonuçları değerlendirildiğinde, her iki örnek için, nitrit ve fosfat tespit edilmezken nitrat ve florürün Sağlık Bakanllğı tarafindan belirlenen limitlerin altında olduğu tespit edilmiştir. Her iki örnekte de amonyum değerinin $0.5 \mathrm{mg} / \mathrm{L}$, magnezyum miktarının $77 \mathrm{mg} / \mathrm{L}$ civarında, klorür miktarının ise $50 \mathrm{mg} / \mathrm{L}$ civarında olduğu görülmüştür. İki örneğin kalsiyum miktarı yukarıda da bahsedilen kalsiyumlu ibaresinin yazılabilmesi için uygun olduğu tespit edilmiştir. İki örneğin sodyum miktarlarının birbirinden farklı olduğu görülmüsstür. Bunun sebebi olarak, sodyum değeri maden sularında mevsime göre, 
yağ1ş durumuna göre, ya da kaynakların bulunduğu yüzeyin jeolojik durumuna göre değişkenlik gösterdiği söylenilebilir. Aroma katkılı maden suyu çeşitlerinin analiz sonucu Çizelge 4'teki gibidir.

Çizelge 3. Sade maden suyu analiz sonuçları Table 3 Anions and cations concentration in mineral water

\begin{tabular}{|c|c|c|c|c|c|}
\hline \multicolumn{2}{|c|}{$\begin{array}{l}\text { ANALIT } \\
(\mathrm{mg} / \mathrm{L})\end{array}$} & \multirow{2}{*}{$\frac{75-A}{}$} & \multirow{2}{*}{$\frac{\% \mathrm{RSD}}{4.11}$} & \multirow{2}{*}{$\begin{array}{c}\text { C-89 } \\
1.03\end{array}$} & \multirow{2}{*}{$\frac{\% \mathrm{RSD}}{2.24}$} \\
\hline \multirow{6}{*}{$\begin{array}{l}\text { Z } \\
0 \\
\text { Z⿱ } \\
z\end{array}$} & $F^{-}$ & & & & \\
\hline & $\mathrm{Ct}$ & 57.23 & 1.97 & 51.90 & 0.44 \\
\hline & $\mathrm{NO}_{2}^{-}$ & T.E. & T.E. & T.E. & T.E. \\
\hline & $\mathrm{NO}_{3-}^{-}$ & 0.55 & 12.74 & 0.44 & 1.61 \\
\hline & $\mathrm{PO}_{4}^{-}$ & T.E. & T.E. & T.E. & T.E. \\
\hline & $\mathrm{SO}_{4}^{2-}$ & 35.09 & 1.33 & 24.55 & 0.83 \\
\hline \multirow{5}{*}{ 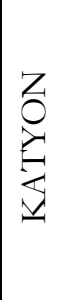 } & $\mathrm{Na}^{+}$ & 189.52 & 0.92 & 165.06 & 1.42 \\
\hline & $\mathrm{NH}_{4}{ }^{+}$ & 0.56 & 21.03 & 0.57 & 0.55 \\
\hline & $K^{+}$ & 32.02 & 1.37 & 27.97 & 1.78 \\
\hline & $M g^{2+}$ & 77.62 & 1.61 & 78.76 & 0.92 \\
\hline & $\mathrm{Ca}^{2+}$ & 152.78 & 0.96 & 153.20 & 1.13 \\
\hline
\end{tabular}

Aromalı maden sularında ise, nitrit, fosfat ve amonyum tespit edilmezken nitrat ve florürün Sağlık Bakanlığ1 tarafindan belirlenen limitlerin altın olduğu gözlenmiştir. Magnezyum miktarının $60 \mathrm{mg} / \mathrm{L}$ civarında tespit edilirken. Yine tüm örneklerde sodyum miktarı değişkenlik göstermiştir. Genel sonuçlara bakıldığında anyon ve katyon değerlerinin yaklaşı \% \%-10 arasında düşüş gösterdiği görülmüştür. $\mathrm{Bu}$ değişimin sebebi olarak, üretim prosesinde bu tür ürünlerin hazırlanmasında şeker, asitlik düzenleyiciler gibi katk1 maddelerinin kullanilmasinin etkisi gösterilebilir. Bu katk1 maddeleri toplam hacme etki ettiğinden dolayı böyle bir azalmaya sebep olmaktadırlar. Meyve katkilı maden suyu çeşitlerinin analiz sonucu Çizelge 5’teki gibidir.

Meyve katkılı ürünlerin hiçbirinde, nitrit ve fosfat tespit edilmemiştir. Diğer anyon ve katyon parametrelerinin analiz sonuçlarında, meyvenin türüne göre farkll1ıklar tespit edilmiştir. Bilindiği gibi meyvelerin de anyon ve katyon içerikleri bulunmaktadır. Bu içerikler meyveden meyveye değişkenlik göstermektedir. Bu sebepten dolayı, ürünlerin her çeşidinde anyon ve katyon miktarlarında değişkenlikler tespit edilmiştir. Vitamin katkılı maden suyu çeşitlerinin analiz sonuçları Çizelge 6'daki gibidir.

T.E. Tespit Edilemedi / Undetected

Çizelge 4. Aroma katkılı maden suyu analiz sonuçları

Table 4 Anions and cations concentration in flovared mineral water

\begin{tabular}{|c|c|c|c|c|c|c|c|c|c|c|c|}
\hline \multicolumn{2}{|c|}{$\begin{array}{l}\text { ANALİT } \\
(\mathrm{mg} / \mathrm{L})\end{array}$} & S5 & $\%$ RSD & K7 & $\% \mathrm{RSD}$ & T12 & $\%$ RSD & P1 & $\%$ RSD & Y9 & $\% \mathrm{RSD}$ \\
\hline \multirow{6}{*}{$\begin{array}{l}\text { Z } \\
0 \\
\text { Z) } \\
Z\end{array}$} & $F^{-}$ & 1.06 & 8.87 & 1.44 & 14.72 & 1.54 & 6.31 & 2.69 & 11.22 & 1.99 & 8.85 \\
\hline & $\mathrm{Ct}$ & 44.76 & 2.72 & 40.29 & 1.95 & 43.78 & 7.63 & 42.84 & 2.61 & 39.67 & 3.94 \\
\hline & $\mathrm{NO}_{2}^{-}$ & T.E. & T.E. & T.E. & T.E. & T.E. & T.E. & T.E. & T.E. & T.E. & T.E. \\
\hline & $\mathrm{NO}_{3}$ & 1.93 & 7.06 & 0.43 & 11.32 & 1.26 & 22.68 & 1.05 & 3.15 & 0.69 & 6.98 \\
\hline & $\mathrm{PO}_{4}^{-}$ & T.E. & T.E. & T.E. & T.E. & T.E. & T.E. & T.E. & T.E. & T.E. & T.E. \\
\hline & $\mathrm{SO}_{4}{ }^{2-}$ & 21.52 & 4.92 & 18.29 & 2.59 & 21.66 & 13.32 & 26.32 & 7.53 & 18.65 & 0.26 \\
\hline \multirow{5}{*}{ 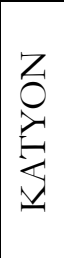 } & $\mathrm{Na}^{+}$ & 162.00 & 8.26 & 172.50 & 8.02 & 139.10 & 1.18 & 152.80 & 0.71 & 156.70 & 2.68 \\
\hline & $\mathrm{NH}_{4}^{+}$ & T.E. & T.E. & T.E. & T.E. & T.E. & T.E. & T.E. & T.E. & T.E. & T.E. \\
\hline & $K^{+}$ & 22.51 & 4.01 & 21.79 & 3.70 & 21.81 & 2.68 & 24.00 & 0.64 & 22.35 & 9.16 \\
\hline & $M g^{2+}$ & 61.56 & 1.12 & 65.50 & 1.22 & 66.23 & 1.90 & 65.17 & 1.15 & 67.74 & 1.16 \\
\hline & $\mathrm{Ca}^{2+}$ & 126.80 & 1.65 & 129.10 & 0.80 & 124.00 & 2.52 & 129.10 & 3.36 & 134.00 & 1.77 \\
\hline
\end{tabular}

T.E. Tespit Edilemedi / Undetected 
Çizelge 5. Meyve Konsantresi katkılı maden suyu analiz sonuçları Table 5 Anions and cations concentration in fruity mineral water.

\begin{tabular}{|c|c|c|c|c|c|c|c|c|c|c|c|c|c|c|c|}
\hline \multicolumn{2}{|c|}{$\begin{array}{l}\text { ANALIT } \\
(\mathrm{mg} / \mathrm{L})\end{array}$} & $5 \mathrm{H}$ & $\%$ RSD & $8 \mathrm{R}$ & $\%$ RSD & $2 \mathrm{~K}$ & $\%$ RSD & 9T & $\%$ RSD & $4 \mathrm{~B}$ & $\%$ RSD & $3 \mathrm{D}$ & $\%$ RSD & Z3 & $\%$ RSD \\
\hline \multirow{6}{*}{$\begin{array}{l}Z \\
0 \\
\text { Ż }\end{array}$} & $F^{-}$ & T.E. & T.E. & 2.19 & 8.06 & 1.51 & 12.19 & 1.48 & 9.65 & 1.50 & 16.76 & T.E. & T.E. & 3.01 & 2.49 \\
\hline & $\mathrm{Ct}$ & 38.55 & 2.83 & 48.01 & 2.05 & 42.89 & 6.23 & 51.67 & 9.52 & 47.19 & 13.77 & 49.24 & 0.80 & 58.82 & 4.29 \\
\hline & $\mathrm{NO}_{2}^{-}$ & T.E. & T.E. & T.E. & T.E. & T.E. & T.E. & T.E. & T.E. & T.E. & T.E. & T.E. & T.E. & T.E. & T.E. \\
\hline & $\mathrm{NO}_{3}$ & T.E. & T.E. & 1.02 & 39.10 & 0.34 & 7.84 & 3.41 & 8.13 & T.E. & T.E. & 0.71 & 7.19 & 1.19 & 7.05 \\
\hline & $\mathrm{PO}_{4}$ & T.E. & T.E. & T.E. & T.E. & T.E. & T.E. & T.E. & T.E. & T.E. & T.E. & T.E. & T.E. & T.E. & T.E. \\
\hline & $\mathrm{SO}_{4}{ }^{2-}$ & 72.11 & 5.28 & 41.81 & 1.67 & 77.95 & 5.76 & 55.08 & 13.91 & 77.43 & 9.80 & 62.30 & 4.51 & 34.43 & 5.75 \\
\hline \multirow{5}{*}{$\begin{array}{l}z \\
0 \\
z \\
\underline{Z} \\
\underline{\Delta}\end{array}$} & $\mathrm{Na}^{+}$ & 167.80 & 1.53 & 157.90 & 5.87 & 147.40 & 3.03 & 157.60 & 3.51 & 166.10 & 0.12 & 151.60 & 1.10 & 155.30 & 8.24 \\
\hline & $\mathrm{NH}_{4}^{+}$ & 2.72 & 2.78 & 6.01 & 1.06 & 2.69 & 2.07 & 1.92 & 1.02 & T.E. & T.E. & 6.38 & 1.24 & T.E. & T.E. \\
\hline & $K^{+}$ & 69.36 & 4.77 & 156.80 & 1.47 & 158.50 & 1.92 & 185.60 & 1.44 & 125.30 & 0.60 & 132.30 & 1.51 & 118.80 & 2.33 \\
\hline & $\mathrm{Mg}^{2+}$ & 64.16 & 1.60 & 63.48 & 2.25 & 63.31 & 2.00 & 65.88 & 1.79 & 65.74 & 1.90 & 49.19 & 1.50 & 61.85 & 5.68 \\
\hline & $\mathrm{Ca}^{2+}$ & 125.40 & 1.38 & 131.90 & 2.53 & 124.40 & 0.48 & 128.80 & 1.20 & 133.80 & 1.10 & 129.30 & 1.14 & 124.70 & 5.18 \\
\hline
\end{tabular}

T.E. Tespit Edilemedi / Undetected

Çizelge 6. Vitamin katkılı maden suyu analiz sonuçları

Table 6 Anions and cations concentration in mineral water with vitamin

\begin{tabular}{|c|c|c|c|c|c|c|c|}
\hline \multicolumn{2}{|c|}{$\begin{array}{l}\text { ANALİT } \\
(\mathrm{mg} / \mathrm{L})\end{array}$} & PT8 & $\% \mathrm{RSD}$ & YD4 & $\%$ RSD & KL5 & $\%$ RSD \\
\hline \multirow{6}{*}{$\begin{array}{l}\text { Z } \\
0 \\
\text { Z }\end{array}$} & $F^{-}$ & T.E. & T.E. & T.E. & T.E. & T.E. & T.E. \\
\hline & $\mathrm{Cl}$ & 41.10 & 22.04 & 37.10 & 2.94 & 35.20 & 8.69 \\
\hline & $\mathrm{NO}_{2}^{-}$ & T.E. & T.E. & T.E. & T.E. & T.E. & T.E. \\
\hline & $\mathrm{NO}_{3}$ & T.E. & T.E. & T.E. & T.E. & T.E. & T.E. \\
\hline & $\mathrm{PO}_{4}^{-}$ & T.E. & T.E. & T.E. & T.E. & T.E. & T.E. \\
\hline & $\mathrm{SO}_{4}^{2-}$ & 21.20 & 15.07 & 25.10 & 11.38 & 20.90 & 7.32 \\
\hline \multirow{5}{*}{ 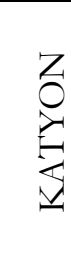 } & $N a^{+}$ & 155.00 & 2,77 & 161,00 & 3,43 & 159,00 & 0,91 \\
\hline & $\mathrm{NH}_{4}^{+}$ & T.E. & T.E. & 1,7 & 1,29 & T.E. & T.E. \\
\hline & $K^{+}$ & 26.10 & 1,54 & 39,20 & 3,91 & 25,90 & 0,36 \\
\hline & $M g^{2+}$ & 60.80 & 0,40 & 61,00 & 1,78 & 56,80 & 1,00 \\
\hline & $\mathrm{Ca}^{2+}$ & 126.00 & 1,26 & 126,00 & 2,22 & 120,00 & 0,32 \\
\hline
\end{tabular}

T.E. Tespit Edilemedi / Undetected

Vitamin katkılı ürünlerde ise genel olarak, florür, klorür, nitrit, nitrat, fosfat ve bir ürün hariç amonyum tespit edilememiştir. Yine yukarıda bahsedildiği gibi kullanılan hammaddelerden dolay1 \%5-10 arasinda anyon ve katyon değerlerinde düşüş görülmüştür.
Çizelge 7'de tüm gruplardan birer örneğin analiz sonuçları verilmiştir. Genel bir değerlendirme yapıldığında meyve katkılı maden suyunun bazı parametreleri hariç diğer ürünlerde \%5-10 arasında azalma söz konusudur. Meyve katkilı maden sularında kesin bir sonuç söylenmesi 
zordur. Çünkü her meyvenin içeriği kendine özgüdür. Hatta bu içeriklere göre meyvelerde orijin çalışmaları yapılmaktadır. Bu yüzden her bir meyve konsantresinin son ürüne yaptığ katk1 farklıdır.

Çizelge 7. Her ürün grubu için karşılaştırılması sonuç çizelgesi

Table 7 Comparison of anion cation results in all groups of mineral water samples

\begin{tabular}{|c|c|c|c|c|c|c|c|c|c|}
\hline \multicolumn{2}{|c|}{$\begin{array}{l}\text { ANALİT } \\
(\mathrm{mg} / \mathrm{L})\end{array}$} & C-89 & $\% \mathrm{RSD}$ & S5 & $\%$ RSD & PT8 & $\% \mathrm{RSD}$ & 9T & $\% \mathrm{RSD}$ \\
\hline \multirow{6}{*}{$\begin{array}{l}Z \\
0 \\
\vdots \\
z \\
z\end{array}$} & $F^{-}$ & 1.03 & 2.24 & 1.06 & 8.87 & T.E. & T.E. & 1.48 & 9.65 \\
\hline & $\mathrm{Cl}$ & 51.90 & 0.44 & 44.76 & 2.72 & 41.10 & 22.04 & 51.67 & 9.52 \\
\hline & $\mathrm{NO}_{2}^{-}$ & T.E. & T.E. & T.E. & T.E. & T.E. & T.E. & T.E. & T.E. \\
\hline & $\mathrm{NO}_{3}$ & 0.44 & 1.61 & 1.93 & 7.06 & T.E. & T.E. & 3.41 & 8.13 \\
\hline & $\mathrm{PO}_{4}^{-}$ & T.E. & T.E. & T.E. & T.E. & T.E. & T.E. & T.E. & T.E. \\
\hline & $\mathrm{SO}_{4}{ }^{2-}$ & 24.55 & 0.83 & 21.52 & 4.92 & 21.20 & 15.07 & 55.08 & 13.91 \\
\hline \multirow{5}{*}{ 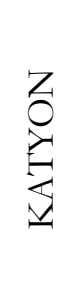 } & $\mathrm{Na}^{+}$ & 165.10 & 1.42 & 162.00 & 8.26 & 155.00 & 2.77 & 157.60 & 3.51 \\
\hline & $\mathrm{NH}_{4}{ }^{+}$ & 0.57 & 0.55 & T.E. & T.E. & T.E. & T.E. & 1.92 & 1.02 \\
\hline & $K^{+}$ & 27.97 & 1.78 & 22.51 & 4.01 & 26.10 & 1.54 & 185.60 & 1.44 \\
\hline & $\mathrm{Mg}^{2+}$ & 78.76 & 0.92 & 61.56 & 1.12 & 60.80 & 0.40 & 65.88 & 1.79 \\
\hline & $\mathrm{Ca}^{2+}$ & 153.20 & 1.13 & 126.80 & 1.65 & 126.00 & 1.26 & 128.80 & 1.20 \\
\hline
\end{tabular}

T.E. Tespit Edilemedi / Undetected

Günümüzde teknolojinin gelişmesi ile gida sektöründe de çeşitlilik artmıştır. Tüketiciye gıda güvenliğine uygun ve tercih edilir ürünler sunmak gıda sektöründeki firmaların en önemli görevlerinden biridir. Tüketiciler herhangi bir gidayı alırken, fonksiyonel olup olmadığına da dikkat etmektedir. Günümüzün getirdiği trendler ile ürün içerisindeki mineral, vitamin gibi yararlı bileşenlerin miktarının fazla olması ürünü pazarda tercih edilir kılmaktadır. Sonuçlardan yola çıkılarak, 'doğal mineralli su' ibaresi taşıyan bu ürünlerin gerçekten mineralli su ile hazırlandığ1 görülmektedir. Şöyle ki; aroma katkılı maden suyunda klor konsantrasyonu $44.76 \mathrm{mg} / \mathrm{L}$, sodyum konsantrasyonu $162.00 \mathrm{mg} / \mathrm{L}$, kalsiyum miktar1 ise $126.80 \mathrm{mg} / \mathrm{L}$ tespit edilmiştir. Yine aynı şekilde vitamin katkılı maden suyunda klor konsantrasyonu $\quad 37.10 \mathrm{mg} / \mathrm{L}, \quad$ sodyum konsantrasyonu $161.00 \mathrm{mg} / \mathrm{L}$, kalsiyum miktarı $126.00 \mathrm{mg} / \mathrm{L}$ tespit edilmiştir. Son olarak meyve katk1lı maden suyunda klor konsantrasyonu 48.01 $\mathrm{mg} / \mathrm{L}$, sodyum konsantrasyonu $157.90 \mathrm{mg} / \mathrm{L}$, kalsiyum miktarı $131.20 \mathrm{mg} / \mathrm{L}$ tespit edilmiştir. Öte yandan, katkilı maden sularının anyon katyon değerlerinde standart maden sularına göre hammadde ilavesinden kaynaklanan \%5-10 arasinda daha az minerale sahip olduğu görülmektedir. Bu azalmada bile ürün içerisindeki mineral miktarı diğer sınıftaki gazlı ve gazsız içecek ürünlerine kıyasla yükssektir. Bunun dışında meyve katk1lı maden sularında meyveden gelen minerallerin son ürüne etki ettiği de açıça görülmektedir. Meyve katkılı maden sularında her bir mineral için ortalama değer söylemek mümkün değildir. Çünkü her meyvenin vitamin ve mineral içeriği o meyveye has olduğu için son üründe de farklı mineral içeriğine sebep olmuştur. Biyoyararlılık açısından suyun vücutta emiliminin yüksek olduğu düşünülürse, maden suyu mineral bakımından epey zengin bir gida ürünüdür. Maden suyu bulunduğu coğrafi şartlara göre mineral değeri değişen bir gida ürünüdür. Maden suyu kaynağının kendine has mineral özellikleri ve meyvelerden gelecek olan mineraller ile zengin 
içeriğe sahip, porsiyon kontrolü yapılabilen ürünler tüketiciye sunulabilir. Bu tür geliştirilen fonksiyonel ürünler ile ülkemizdeki maden suyu tüketimi daha da üst seviyelere çıkarılabilir. Birçok hastalığa sebep olan makro minerallerin alınımı, yine geliştirilen fonksiyonel ürünler ile arttır1labilir.

Ayrıca benzer ürün grubundakiler için çalışmanın sonuçlarının kalite kontrol performansları açısından verimli değerlendirme yapılmasına katkı sağlayacaktır. Özellikle ürünlerin son kullanma sürelerine göre içeriklerindeki değişimler incelenerek raf ömrü uzatılması ile alakalı yeni proje çalışmalarına da yol göstermesi mümkündür.

\section{TEŞEKKÜR}

Çalışma boyunca laboratuvardaki tüm imkânların kullanilmasinda ayrica maddi ve manevi desteklerini esirgemeyen Ar\&Ge Müdürü Tuğba ŞİMŞEK ve Ar\&Ge Yöneticisi Mustafa Çağlar ERCAN bașta olmak üzere ULUDAĞ İÇECEK AR\&GE MERKEZI ailesine sonsuz teşekkürlerimi iletirim.

\section{KAYNAKLAR}

Anonymous (2013). Doğal Mineralli Sular Hakkında Yönetmelik. T.C. Sağlık Bakanlığı 07 Mart 2013 tarihli ve 25657 sayll Resmî Gazete, Ankara.

Annonymous (2007). Su, Mineral ve Esas Elementlerin Vektörü. Danone Nutritopics Magazine, https://dergipark.org.tr/download/ article-file/78395 (Accessed: 23.05.2019).

ASTM D6919-03 (2017). https://www.astm.org/ DATABASE.CART/HISTORICAL/D6919-

03.htm (Accessed: 23.05.2019)

Balcığulları A. (2014). Evliya Çelebi'nin Seyahatnamasei'nde Anadolu şifalı suları ve günümüzün termal turizmi. Türkiye Sosyal Arastırmalar Dergisi, 173(173), 287-306.

Cataldi T. R. I., Angelotti M., D'Erchia L., Altieri G., Di Renzo G. C. (2002). Ion-exchange chromatographic analysis of soluble cations, anions and sugar in milk whey. Eur Food Res
Technol, 216, 75-82, DOI: 10.1007/s00217-0020598-7.

EPA 300.0 (1993). https://www.epa.gov/sites/ production/files/2015-08/documents/method_ 300-0_rev_2-1_1993.pdf (Accessed: 23.05.2019).

FAO Water Statistical Databases (2011). http://www.fao.org. (Accessed: 24.05.2019).

Gatarska A., Tonska E., Ciborska J. (2016). Natural mineral bottled waters available on the polish market asa source of minerals fort he consumers. Part 1. Calcium and magnesium, National Institute of Public Health. 67(1), 1-8.

Gezer N. N. (2016). Sade ve aroma içeren doğal mineralli maden sularındaki ağır metal düzeylerinin toksikolojik açıdan değerlendirilmesi, Ankara Üniversitesi Disiplinleraras1 Adli Bilimler Anabilim Dalı Yüksek Lisans Tezi, Ankara, Türkiye, 119 s.

Gültekin F., Dilek R. (2005). Gümüşhane yöresi mineralli su kaynaklarını iz element ve radyoaktivite içerikleri. Jeoloji Mühendisliği Dergisi, 29(1), 36-43, DOI: 10.17714/gufbed. 2016.06.002.

Kara E., Akı1 M., Andsoy I. I., Acat M., Güngör T. (2012). Müsabaka arası içilen maden suyu serum elektrolit düzeylerine etkisi. Selçuk Üniversitesi Beden Eg̈itimi ve Spor Bilimleri Dergisi, 14(1), 18-21.

Kızıloğlu R., Kızılaslan H., (2013). Maden suyu talebini etkileyen faktörlerin tobit modeli ile analizi: Beypazanı ilçesi örneği. Gaziosmanpașa Üniversitesi Ziraat Fakültesi Dergisi, 30(2), 80-85, DOI: $10.13002 /$ jafag303.

Kopar İ., (2002). Erdemli (Kayseri) maden suyu kaynağının rekreasyon alanı olarak planlanması. Doğu Coğrafya Dergisi, 7(7), 89-107.

Korkmaz H., Karataş A. (2011). Hatay ili mineralli su kaynakları. Fiziki Coğraya Araştormalar; Sistematik ve Bölgesel, Türk Coğrafya Kurumu Yaymlar, 5, 393-340.

Maraver F., Vitoria I., Ferrira-Pego C., Armijo F., Salas-Salvad J. (2015). Magnesium in tap and bottked mineral water in Spain and its contribution to notritional recommendations. 
Nutricion Hospitalaria, 31(5), 2297-2312, DOI: 10.3305/nh.2015.31.5.8589.

Mete M., Altıner D. D. (2017) Eriştenin farklı un katk1ları ile zenginleştirilmesi. Akademik Gıda, 16(2), 252-256, DOI: 10.24323/akademikgida.449870.

Michalski R. (2006). Ion chromatography as a reference method for determination of inorganic ions in water and wastwater. Crit. Rev. Anal. Chem., 36, 107-127, DOI:10.1080/10408340600713678.

Ramza N., Feroze N., Kazmi M., Ashraf M. A., Hasan S. (2012). Performance analysis of cation and anion exchangers in water treatment plant: an industrial case study. Pol J Chem Technnol, 14(2), 3541, DOI: $10.2478 \mathrm{v} / 10026-012-0068-3$.
Samur G. (2008). Vitaminler, Mineraller ve Sağlığımız. https://sbu.saglik.gov.tr/Ekutuphane /kitaplar/B\%202.pdf (Accessed: 23.05.2019)

T.C. Sağlık Bakanlığ1 Doğal Mineralli Sular Rehber Kitab1 (2008). https://hsgm.saglik.gov.tr /depo/birimler/cevre-sagligi/1-su guvenligi/ Kitaplar/Dogal_Mineralli_Sular_Rehber_Kitabi. pdf (Accessed: 23.05.2019)

Toroğlu E., Ceylan S. (2013). Niğde yöresi kaplıca, içmece ve doğal mineralli suları, sorunlar ve öneriler. Doğu Coğrafya Dergisi, 18(30), 47-69.

TURKSTAT (2011). Survey results for household consumption expenses. http:/www.turkstat.gov.tr (Accesed: 24.05.2019). 